Original Research Article

\title{
Anesthetic potential of lidocaine/prilocaine cream versus placebo before venepuncture
}

\author{
Varsha P. Gajbhiye ${ }^{1 *}$, Lamture Y. R. ${ }^{2}$
}

${ }^{1}$ Department of Pharmacology, ${ }^{2}$ Department of Surgery, J.N. Medical College, Wardha, Maharashtra, India

Received: 27 September 2018 Accepted: 26 October 2018

\section{*Correspondence to: \\ Dr. Varsha P. Gajbhiye, Email: dryrlamture@ yahoo.co.in}

Copyright: (C) the author(s), publisher and licensee Medip Academy. This is an openaccess article distributed under the terms of the Creative Commons Attribution NonCommercial License, which permits unrestricted noncommercial use, distribution, and reproduction in any medium, provided the original work is properly cited.

\begin{abstract}
Background: Pain associated with venepuncture has long been accepted as an unavoidable consequence. Many studies show reducing pain during venepuncture after application of prilocaine/lignocaine, but there are few studies that has depicted, the depth of anesthesia produced by prilocaine/lignocaine tends to be too superficial for the reducing the pain during venepuncture. These two scenarios were debatable. Therefore, authors planned a study to assess anesthetic potential of lidocaine /prilocaine cream versus placebo before venepuncture with help of VAS in an adult patient who were drawn blood sample for investigation purposes.

Methods: Prospective interventional study. All adult patient for blood sampling from surgery OPD to central laboratory were included in study. Site of venepuncture selected in both control and study group was left cubital fossa. 30 patients selected in study group received lignocaine/prilocaine locally, 30min prior to venepuncture which was later covered with occlusive tape, whereas 30 control group patient received normal saline locally as placebo. The extent of pain was assessed by patient on $10 \mathrm{~cm}$ visual analogue scale (VAS) with end points of $0 \mathrm{~cm}$ rated as no pain and the points of $10 \mathrm{~cm}$ as intolerable pain.

Results: A total of 60 patient were randomly selected who were referred from surgery OPD for blood sampling. Other 30 patient were applied normal saline as placebo and 30 patient with lignocaine and prilocaine cream. In the control group there were 30 patients ( 5 female and 25 male). In the study group there were 30 patients ( 8 females and 22 males). The level of pain among study group is as follows: mild 22, moderate 7, worst 1 and in control group: no pain 0 , mild 5 , moderate 14 and worst pain 1. Statistical analysis between outcome of two groups done by calculating chi-square test. Chi- square test was 20.0263. P value is 0.000168 . Hence the result is significant at $\mathrm{p}<0.05$.

Conclusions: The present study shows that prilocaine-lidocaine cream reduces the pain of needle puncture in adults and facilitates the procedure of venous blood sampling.
\end{abstract}

Keywords: Prilocaine, Venepuncture, VAS score

\section{INTRODUCTION}

Pain associated with venepuncture has long been accepted as an unavoidable consequence. Fear and pain can make the insertion of intravenous needles for blood sampling a traumatic experience for the all the patient and a difficult and time-consuming task for the physician and nurse. A topical preparation that can be applied to the skin without discomfort and which alleviates pain from needle puncture would be helpful to both patients and staff.
If pain of venous blood sampling reduces, success rate will be greater, blood vessels will be damaged less frequently and access to other vessels will be more possible. Various treatment methods and strategies have been suggested for pain reduction including iontophoresis, topical treatment, dermal patches, among which topical treatment is more tolerable and affordable. ${ }^{1,2}$

Topical anesthetics usually consist of a concentrated form of anesthetic that can be absorbed transdermally. The 
anesthetic is applied to normal intact skin for a specified length of time (usually an hour or more) to allow the anesthetic to penetrate the skin at the application site. This has been shown to significantly minimize or eliminate pain from the venepuncture. ${ }^{3}$ Topical anesthetics work peripherally by numbing the area of the body that is innervated by that nerve. They do not cause unconsciousness, as do general anesthetics used for surgery. These products vary in their active ingredients, mechanism of action, instruction. ${ }^{4}$

Prilocaine $(2.5 \%)$-lidocaine $(2.5 \%)$ is a eutectic mixture; means that melting point of two agent reduces when mix with each other. Consequently, they will form a eutectic liquid at temperature higher than $16-17^{\circ} \mathrm{C}$. This makes a concentration gradient on the skin that facilitates the absorption. This provides sufficient local anesthesia in variety of painful superficial procedure including superficial surgery, laser surgery, epilation, cautery of condylomata and venepuncture. ${ }^{5}$ Also it represents favourable tolerability profile with transient and mild skin blanching.

Visual Analogue Scale (VAS) is a measurement instrument that tries to measure a characteristic or attitude that is believed to range across a continuum of values and cannot easily be directly measured. ${ }^{6}$ It is often used in epidemiologic and clinical research to measure the intensity or frequency of various symptoms.

A higher score indicates greater pain intensity. Pain intensity is described as none, moderate, or worst possible, the following cut points on the pain VAS have been recommended: no pain $(02 \mathrm{~cm})$, mild pain $(2-5)$, moderate pain $(6-8 \mathrm{~cm})$, and worst pain $(8-10 \mathrm{~cm}){ }^{7}$

Many studies show reducing pain during venepuncture after application of prilocaine/lignocaine, but there are few studies that has depicted, the depth of anesthesia produced by prilocaine/lignocaine tends to be too superficial for the reducing the pain during venepuncture. ${ }^{8,9}$ These two scenarios were debatable. Therefore, we planned a study to assess anesthetic potential of lidocaine/prilocaine creame versus placebo before venepuncture with help of VAS in an adult patient who were drawn blood sample for investigation purposes.

\section{METHODS}

The design of this study was prospective interventional study conducted at AVBRH (Acharya Vinoba Bhave rural hospital) Sawangi, Meghe. This study was approved by the institute ethics committee of our hospital and informed consent was obtained before procedure. Total of 30 control and 30 in study group were included in the study. All adult patient for blood sampling from surgery outpatient department to central laboratory were included in study. Using systemic sampling technique, subjects were alternatively placed in control and experimental group. All the odd numbered subjects were included in control group while the even numbered subjects were included in experimental group.

Site of venepuncture selected in both control and study group was left cubital fossa. In experimental group $2.5 \%$ prilocaine -lidocaine $2.5 \%$ was applied a $5 \times 5 \mathrm{~cm}$ over inner aspect of left cubital fossa for $30 \mathrm{~min}$. The time of administration was recorded which was calculated after application of prilocaine-lidocaine. 30 patients selected in study group received lignocaine/prilocaine locally,30 min prior to venepuncture which was later covered with occlusive tape, whereas 30 control group patient received normal saline locally as placebo.

Pain intensity is described as none, moderate, or worst possible, the following cut points on the pain VAS have been recommended: no pain $(0-2 \mathrm{~cm})$, mild pain $(2-5)$, moderate pain $(6-8 \mathrm{~cm})$, and worst pain $(8-10 \mathrm{~cm}){ }^{7}$

\section{Inclusion criteria}

- All adult patient advised for blood sampling from surgery outpatient department to central laboratory

- Both genders.

\section{Exclusion criteria}

- $\quad$ Age 0-14

- In patient department

- Skin infection in left and right cubical fossa

- Uncooperative patient.

Adverse events were evaluated for all patient included in study and control group. This includes skin reaction such as blanching and local erythema which was assessed at the time of venepuncture and after removal of occlusive tape.

\section{Statistical analysis}

Data analysis was performed using statistical software (SPSS, version 18.0 for Windows). Comparison between the two groups was performed using Chi-square test. Statistical significance was accepted at a $\mathrm{P}$ value $<0.05$.

\section{RESULTS}

A total of 60 patient were randomly selected from surgery outpatient department (OPD) for blood sampling. Out of this 30 included in study group of lidocaine /prilocaine and Other 30 patients in control group of normal saline as placebo.

In the control group there were 30 patients ( 5 female and 25 male). In the study group there were 30 patients ( 8 females and 22 males).

The level of pain among study group is as follows: mild 22, moderate 7 , worst 1 and in control group: no pain 0 , mild 5 , moderate 14 and worst pain 1 . 
Statistical analysis between outcome of two groups done by calculating chi-square test. Chi- square test was 20.0263. $\mathrm{P}$ value is 0.000168 . Hence the result is significant at $\mathrm{p}<0.05$.

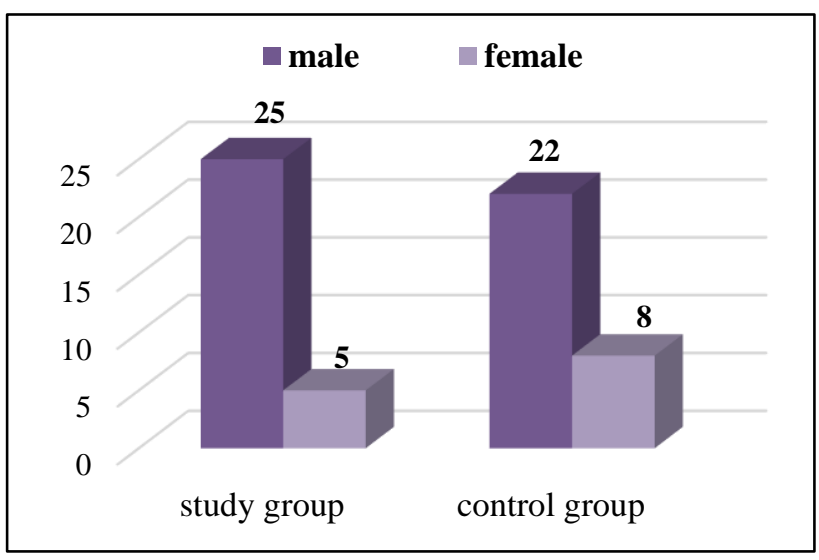

Figure 1: Gender distribution.

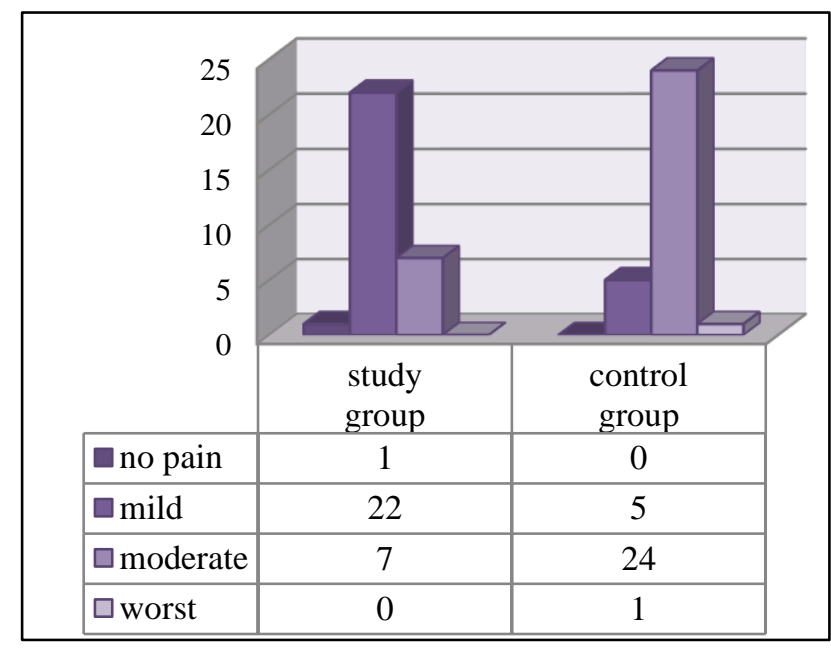

Figure 2: VAS score evaluation.

\section{DISCUSSION}

Many attempts have been made to obtain a suitable formulation for effective topical anesthesia. Examples of preparations that have been tested are 1idocaine., ${ }^{9,10}$ benzocaine, combinations of local anesthetics with dimethylsulphoxide (DMSO) and ketocaine in alcoholic solutions. ${ }^{11}$ Physical methods such as iontophoresis have also been tried to increase the penetration. ${ }^{12,13}$ No formulation has yet gained wide acceptance mainly due to either poor pain-relieving effect, inconvenient application, irritation or toxic reactions. In adults prilocaine-lignocaine has been shown to penetrate intact skin and abolish the pain response to pin-prick. It has even been possible to perform superficial skin surgery without any other analgesia. ${ }^{14}$

A total of 60 patient were randomly selected included in present study. In the control group there were 30 patients ( 5 female and 25 male). In the study group there were 30 patients ( 8 females and 22 males). The pain score among study group was as follows: mild 22 , moderate 7 , worst 1 and in control group: no pain 0 , mild 5, moderate 14 and worst pain 1 .

Statistical analysis between outcome of two groups (pain scores) done by calculating chi-square test. Chi- square test was 20.0263. $\mathrm{P}$ value is 0.000168 . Hence the result is significant at $p<0.05$. Suggesting the efficacy of lignocaine-prilocaine combination in achieving anesthetic effect before venepuncture.

The pain scores recorded in present study were much lower in study group than control group. This is similar to previous two studies done by Harrison et al, and Armstrong et al, who also has used $10 \mathrm{~cm}$ visual analogue scale. ${ }^{15,16}$

Another study done by Langham BT et al, showed no significant difference in pain scores in study and control group. ${ }^{17}$ This study did not correlate to present study. The difference could be due to fact that in their study the participants were surgical patient in operation theatre where lignocaine-prilocaine was applied $5 \mathrm{~min}$ before venepuncture with no occlusive bandage. In present study lignocaine-prilocaine cream with occlusive dressing was applied 30min prior to venepuncture. This time is adequate for its analgesic action. This alone may account for the differences in the pain scores.

In present study there were no significant difference between groups regarding gender. A study done by Dexter et al, shows decrease in pain scores in female as compared to male which was not seen in our study. ${ }^{18}$

Hence this study proves that lidocaine-prilocaine cream has good analgesic effect in relieving pain of venepuncture.

\section{ACKNOWLEDGEMENTS}

Authors would like to acknowledge Pharmacology, Surgery Department and Central Laboratory for kind cooperation to complete this work.

\section{Funding: No funding sources}

Conflict of interest: None declared

Ethical approval: The study was approved by the Institutional Ethics Committee

\section{REFERENCES}

1. Ramsay MA. A survey of pre-operative fear. Anaesthesia. 1972 Oct;27(4):396-402.

2. Blom GE. The reactions of hospitalized children to illness. Pediatrics. 1958 Sep 1;22(3):590-600.

3. Brechner VL, Cohen DD, Pretsky I. Dermal anesthesia by the topical application of tetracaine base dissolved in dimethyl sulfoxide. Ann New York Acad Sci. 1967 Mar;141(1):524-31.

4. Dalili H, Adriani J. The efficacy of local anesthetics in blocking the sensations of itch, burning, and pain in 
normal and "sunburned" skin. Clin Pharmacol Therapeutics. 1971 Nov 1;12(6):913-9.

5. Ehrenström Reiz R. NA GM, Reiz SL. EMLA-a eutectic mixture of local anesthetics for topical anaesthesia. Acta Anaesthesiol Scand. 1982 Dec;26(6):596-8.

6. Giovannetti JA, Bennet CR. Assessment of allergy to local anesthetics. Am Dent Assoc. 1979;98:701-6.

7. Scott J, Huskisson EC. Vertical or horizontal visual analogue scales. Ann Rheumatic Dis. 1979 Dec $1 ; 38(6): 560$.

8. Daneshkazemi A, Abrisham SM, Daneshkazemi P, Davoudi A. The efficacy of eutectic mixture of local anesthetics as a topical anesthetic agent used for dental procedures: a brief review. Anesthesia Essays Res. 2016 Sep;10(3):383.

9. Menter A, Black-Noller G, Riendeau LA, Monti KL. The use of EMLA cream and 1\% lidocaine infiltration in men for relief of pain associated with the removal of genital warts by cryotherapy. J Am Acad Dermatol. 1997 Jul 1;37(1):96-100.

10. Kumar S, Kumar S, Ganesamoni R, Mandal AK, Prasad S, Singh SK. Dimethyl sulfoxide with lignocaine versus eutectic mixture of local anesthetics: prospective randomized study to compare the efficacy of cutaneous anesthesia in shock wave lithotripsy. Urological Res. 2011 Jun 1;39(3):181-3.

11. Russo JE, Lipman AG, Comstock TJ, Page BC, Stephen RL. Lidocaine anesthesia: comparison of iontophoresis, injection, and swabbing. Am J Health System Pharmacy. 1980 Jun 1;37(6):843-7.
12. Hallen B, Carlsson P, Uppfeldt A. Clinical study of a lignocaine-prilocaine cream to relieve the pain of venepuncture. $\mathrm{Br}$ J Anaesthesia. 1985 Mar $1 ; 57(3): 326-8$.

13. Pettersson LO. Percutaneous anaesthesia for taking split skin grafts. Scand J Plastic Reconstructive Surg. 1977 Jan 1;11(1):79-82.

14. Rapperport S. Adjunctive uses for iontophoresis. In: Fifth International Congress of Plastic and Reconstructive Surgery 1971:797-802.

15. Harrison N, Langham BT, Bogod DG. Appropriate use of local anesthetic for venous cannulation. Anaesthesia. 1992 Mar;47(3):210-2.

16. Armstrong P, Young C, McKeow D. Ethylchloride and venepuncture pain: a comparison with intradermal lignocaine. Can J Anaesth. 1990;37:656-8.

17. Langham BT, Harrison DA. Local anesthetic: does it really reduce the pain of insertion of all sizes of venous cannula?. Anaesthesia. 1992 Oct;47(10):890-1.

18. Dexter F, Chestnut DH. Analysis of statistical tests to compare visual analog scale measurements among groups. Anesthesiology: J Am Soc Anesthesiologists. 1995 Apr 1;82(4):896-902.

Cite this article as: Gajbhiye VP, Lamture YR. Anesthetic potential of lidocaine/prilocaine cream versus placebo before venepuncture. Int J Basic Clin Pharmacol 2018;7:2401-4. 